\title{
Crescimento, sobrevivência e trocas gasosas de mudas de Eucalyptus dunnii Maiden submetidas a regimes de irrigação e aplicação de hidrogel
}

\author{
Growth, survival and gas exchange in Eucalyptus dunnii Maiden plants submitted to \\ irrigation regimes and hydrogel application
}

\author{
Dionéia Felippe ${ }^{1} \bullet$ Marcio Carlos Navroski ${ }^{1}$ Natália Saudade de Aguiar² $\bullet$ \\ Mariane de Oliveira Pereira ${ }^{1} \bullet$ Carolina Moraes $^{1} \bullet$ Milena Amaral $^{1}$
}

\begin{abstract}
The addition of water-repelling polymers aims to increase water retention capacity in the soil, providing higher seedling survival rate and allowing planting at different times of the year. The objective of the present work was to evaluate the effect of hydrogel use on planting Eucalyptus dunnii seedlings in pots, related to different water management, simulating field conditions in a Humic Cambisol soil. The experiment was conducted in a completely randomized design with factorial arrangement (hydrogel and irrigation frequency). The hydrogel factor was composed by the presence or absence of the polymer, and the frequency of irrigation by irrigation only at planting, every 8 days, 4 days and daily. Water stress symptomatology, morphometric aspects, soil water content and gas exchange were evaluated. The hydrogel provided an increase in soil water content and delayed symptoms of water stress, especially when irrigation was less frequent. The addition of the polymer also provided improved seedling quality, more accumulated dry mass. Water stress was a limiting factor for stomatal opening. The lower the water availability, the lower the photosynthesis, stomatal conductance and transpiration values. In general, the results confirm that the addition of hydrogel in the soil optimizes water availability, with the possibility of reducing planting mortality and maximizing plant growth in the initial phase of establishment.
\end{abstract}

Key words: Water-repelling polymer, water deficit, ecophysiology, photosynthesis, symptomatology.

1. Departamento de Engenharia Florestal, Universidade do

Estado de Santa Catarina; Lages, SC, Brasil,

dioneia.felippe@gmail.com; marcio.navroski@

udesc.br; maripereira.florestal@gmail.com;

carolina.moraes1@edu.udesc.br; milenaamaral@live.com

2. Pós-graduação Em Engenharia Florestal, Universiade

Federal do Paraná (UFPR), Curitiba, PR, Brasil,

Recibido: 08/09/2019

talia.saguiar@yahoo.com.br

Aceptado: 28/11/2019

Publicado: 19/12/2019

DOI: $10.18845 / \mathrm{v} 17 \mathrm{i} 40.4902$ 


\section{Resumo}

A adição de polímeros hidroretentores visa aumentar a capacidade de retenção de água no solo, propiciando maior taxa de sobrevivência das mudas e permitindo o plantio em épocas distintas do ano. O objetivo do presente estudo foi avaliar o efeito do uso do hidrogel no plantio de mudas de Eucalyptus dunnii em vasos, relacionado com diferentes manejos hídricos, simulando condições de campo em solo do tipo Cambissolo Húmico. O experimento foi conduzido em delineamento inteiramente casualizado, com arranjo fatorial (hidrogel e frequência de irrigação). $O$ fator hidrogel foi composto por presença ou ausência do polímero, e a frequência de irrigação por irrigação somente no plantio, a cada 8 dias, 4 dias e diariamente. Foram realizadas avaliações da sintomatologia do estresse hídrico, aspectos morfométricos, teor de água no solo e trocas gasosas. O hidrogel proporcionou aumento no teor de água no solo e o adiamento nos sintomas de estresse hídrico, principalmente quando a irrigação foi efetuada com menor frequência. A adição do polímero também proporcionou melhoria na qualidade das mudas, com maior acúmulo de massa seca. O estresse hídrico foi um fator limitante para a abertura estomática. Quanto menor a disponibilidade de água, menores foram os valores de fotossíntese, condutância estomática e transpiração. Em geral, os resultados obtidos confirmam que a adição de hidrogel no solo otimiza a disponibilidade de água, com possibilidade de redução da mortalidade no plantio e maximização do crescimento das plantas na fase inicial de estabelecimento.

Palavras chave: Polímero hidroretentor, déficit hídrico, ecofisiologia, fotossíntese, sintomatologia.

\section{Introdução}

As espécies do gêneroEucalyptus têm se destacado como as mais utilizadas nos programas de reflorestamento, ocupando atualmente no Brasil uma área superior a 5,7 milhões de hectares [1]. Um dos motivos para esse aumento são os programas de melhoramento genético, que produzem materiais específicos para diferentes condições ambientais, que sejam resistentes a doenças bióticas e abióticas, bem como para a produção de madeira de qualidade [2]. Assim, ao longo das últimas décadas se verificaram maior produtividade das florestas de eucalipto, graças ao desenvolvimento de materiais genéticos de maior potencial produtivo [3].

Apesar de ser o gênero mais plantado, a avaliação das áreas de cultivo e a redução das disponíveis levaram o eucalipto para áreas marginais, com baixa disponibilidade de água e solos de baixa fertilidade. A escassez de água é considerada a maior barreira à produtividade agrícola e florestal [4]. O efeito da deficiência hídrica sobre as plantas é complexo, não havendo um mecanismo universal de resistência à seca, pois as plantas respondem por meio de vários processos adaptativos à escassez de água como, por exemplo, pela capacidade de reduzir o potencial hídrico, aliada às adaptações fisiológicas, anatômicas e morfológicas [5].

Durante a fase inicial de desenvolvimento, o déficit hídrico interfere decisivamente no crescimento e aumenta a mortalidade das plantas no campo [6]. Portanto, airrigação das mudas de espécies florestais durante o plantio e, principalmente nas primeiras semanas da implantação é considerada uma operação de fundamental importância em plantios comerciais, sobretudo nas épocas mais secas do ano. Essa atividade exerce influência direta na sobrevivência e no desenvolvimento das mesmas, pois nessa fase as mudas ainda apresentam o sistema radicular pouco desenvolvido, sendo mais susceptíveis à deficiência hídrica [7].

Uma das possibilidades para aumentar a sobrevivência inicial das mudas no pós-plantio é a utilização do hidrogel, pois supre parte da demanda hídrica das plantas na fase crítica [8]. Este produto também contribui para a viabilização do plantio o ano todo, tornando essa operação menos dependente das variações climáticas observadas ao longo do ano. Como possibilita a retenção de água e a sua liberação de maneira gradativa para a planta, pode aumentar a eficiência da irrigação e diminuir o risco da ocorrência de falhas durante o estabelecimento do povoamento florestal.

Desse modo, o objetivo do estudo foi avaliar o efeito do hidrogel no plantio em vasos de mudas de Eucalyptus dunnii, relacionado com diferentes manejos hídricos, buscando fornecer informações sobre a eficiência do uso do hidrogel.

\section{Material e métodos}

O estudo foi realizado entre os meses de setembro e novembro de 2015 , em casa de vegetação do viveiro florestal da Universidade do Estado de Santa Catarina, localizada no município de Lages, SC, Brasil.

As mudas de origem seminal de Eucalyptus dunnii foram adquiridas em um viveiro florestal da região, com aproximadamente 120 dias, estas estavam com médias de altura de cerca de $25,0 \mathrm{~cm}$ e $2,0 \mathrm{~mm}$ de diâmetro de coleto, conforme recomendado por Wendling e Dutra [9]. 
O substrato utilizado foi constituído de solo retirado de 0 a $50 \mathrm{~cm}$ de profundidade em Cambissolo Húmico alumínico argiloso. Foram utilizados vasos de polietileno com 10 I de capacidade. Para redução de erros experimentais, realizou-se com auxílio de uma balança digital a uniformização de $8 \mathrm{~kg}$ de massa de solo e, posteriormente adicionou-se 1,5 I de água, até o solo atingir a capacidade de campo.

O experimento foi conduzido no delineamento inteiramente casualizado (DIC), com 8 repetições, compostas de uma planta, em arranjo fatorial $2 \times 4$. O fator hidrogel foi composto por dois níveis (presença e ausência) e a frequência por quatro níveis, sendo: 0 - irrigação somente no plantio; 1 - irrigação diária; 4 - irrigação a cada 4 dias; e 8 - irrigação a cada 8 dias. Nas irrigações foram utilizadas $300 \mathrm{ml}$ de água em cada vaso.

A hidratação do hidrogel, polímero sintético sólido granulado da Hidroplan-EB尺, com dosagem de 3 $\mathrm{g} \mathrm{l}^{-1}$ foi realizada 30 minutos antes do plantio. Nos tratamentos que compreendiam a presença de hidrogel foram adicionados $300 \mathrm{ml}$ deste, na forma já hidratada, antes da realização do plantio da muda. Nos tratamentos sem o hidrogel foram adicionadas $300 \mathrm{ml}$ de água após o plantio, além do 1,5 I para umedecer o solo, de modo a compensar o volume de água a ser adicionado via hidrogel.

\section{Sintomatologia visual}

Do plantio até $\circ 56^{\circ}$ dia de experimento foram realizadas avaliações diárias da sintomatologia de estresse hídrico. Para a sintomatologia visual foi adotado o critério de análise conforme Navroski et al. [10], sendo anotado o número de dias em que a planta permanecia em cada condição: SEM - dias sem sintomas (planta túrgida, visualmente vigorosa, sem indícios de déficit hídrico); SLM - dias com sintomas leves de murcha; SMM - dias com sintomas moderados (planta em ponto de murcha permanente, com ápice escurecido e curvado); SSM - dias com sintomas severos de murcha (folhas secas ou em abscisão). Para a sobrevivência foi adotado o código NPV- número de dias que a planta permaneceu viva.

\section{Teor de água no solo}

Com o intuito de acompanhar o teor de umidade dos vasos durante o período experimental, determinou-se o teor de água inicial do solo. Antes do plantio das mudas, todos os vasos foram saturados e deixados drenar por duas horas. Coletou-se então uma amostra com aproximadamente $100 \mathrm{~g}$ de solo de cada vaso. As amostras foram separadas e acondicionadas em copos de papel alumínio. A determinação da massa úmida dos vasos foi realizada com o uso de balança de precisão. Após a determinação da massa úmida, as amostras foram encaminhadas à secagem em estufa, na qual ficaram dispostas até o momento de estabilização de suas massas, sendo posteriormente realizada nova pesagem, para determinação da massa seca. Os vasos foram pesados a cada 4 dias, sempre antes da irrigação. Posteriormente, foi calculado o teor de água no solo por meio de equações.

\section{Atributos morfométricos}

Avaliações biométricas de altura e diâmetro do coleto foram realizadas no início e no final (56 dias após a implantação) do experimento. Ao término deste período, quando as mudas sem a irrigação murcharam permanentemente, procedeu-se a coleta da biomassa das plantas por meio de método destrutivo. As amostras foram separadas em raiz, caule e folhas, e acondicionadas em sacos de papel mantidos em estufa com circulação forçada de $\operatorname{ar}\left(65 \pm 3^{\circ} \mathrm{C}\right)$ até atingirem massa constante. Posteriormente, os componentes foram pesados em balança de precisão $(0,01 \mathrm{~g})$ para determinação dos teores de massa seca radicular (MSR), massa seca caulinar (MSC) e massa seca foliar (MSF), em gramas por planta. Para a determinação da área foliar individual, foram coletadas todas as folhas de cada planta. A área foliar foi quantificada com auxílio de um integrador de área foliar LI-COR, modelo LI3000A.

\section{Trocas gasosas}

As avaliações de trocas gasosas foram realizadas com o auxílio de um medidor portátil de fotossíntese LI-COR, modelo LI-6400XT, determinando-se os valores de fotossíntese $(A)$, condutância estomática (gs), transpiração (E), relação entre a concentração intercelular e atmosférica de $\mathrm{CO}_{2}(\mathrm{Ci} / \mathrm{Ca})$ e eficiência no uso da água (WUE), em 4 repetições. A radiação fotossinteticamente ativa (RFA) utilizada durante as medições foi de $700 \mu \mathrm{mol}$ de fótons $\mathrm{m}^{-2} \mathrm{~s}^{-1}$, sendo fornecida por uma fonte luminosa artificial (LI-640040), e o percentual de luz azul de $10 \%$ da RFA. A concentração atmosférica de $\mathrm{CO}_{2}$ oscilou de 390 a $400 \mu \mathrm{mol} \mathrm{mol}{ }^{-1}$. As avaliações foram realizadas a cada sete dias e iniciaram imediatamente após o transplante das mesmas, ocorrendo sempre entre 8:00 e 11:30 horas. Utilizou-se a mesma folha durante todo o período experimental a fim de não haver variação 
Tabela 1. Surgimento dos sintomas de estresse hídrico nas plantas, em dias, avaliado até o $56^{\circ}$ dia após o plantio de Eucalyptus dunnii, em função da presença ou ausência de hidrogel e diferentes frequências de irrigação.

Table 1. Emergence of water stress symptoms, in days, evaluated from planting until the 56th day after planting Eucalyptus dunnii, due to the presence or absence of hydrogel and different irrigation frequencies.

\begin{tabular}{|c|c|c|c|c|c|c|}
\hline \multirow{3}{*}{$\begin{array}{l}\text { Sintomas de } \\
\text { estresse }\end{array}$} & \multirow{3}{*}{ Hidrogel } & \multicolumn{5}{|c|}{ Surgimento dos sintomas (dias) } \\
\hline & & \multicolumn{5}{|c|}{ Frequência de irrigação } \\
\hline & & Plantio (0) & 8 dias & 4 dias & Diária (1) & Média \\
\hline \multirow{2}{*}{ SEM } & Presente & $20,2 \mathrm{Ba}^{*}$ & $52,7 \mathrm{~A} \underline{a}$ & $54,5 \mathrm{Aa}$ & $56,0 \mathrm{Aa}$ & 45,88 \\
\hline & Ausente & $17,8 \mathrm{Bb}$ & $48,7 \mathrm{Ab}$ & $53,6 \mathrm{Aa}$ & $56,0 \mathrm{Aa}$ & 40,00 \\
\hline \multirow{2}{*}{ SLM } & Presente & $28,6 \mathrm{Ba}$ & $53,7 \mathrm{Aa}$ & $54,5 \mathrm{Aa}$ & $56,0 \mathrm{Aa}$ & 48,2 \\
\hline & Ausente & $25,0 \mathrm{Bb}$ & $49,6 \mathrm{Ab}$ & $50,6 \mathrm{Ab}$ & $56,0 \mathrm{Aa}$ & 45,3 \\
\hline \multirow{2}{*}{ SMM } & Presente & $39,5 \mathrm{Ba}$ & $56,0 \mathrm{Aa}$ & $56,0 \mathrm{Aa}$ & $56,0 \mathrm{Aa}$ & 51,9 \\
\hline & Ausente & $36,6 \mathrm{Bb}$ & $56,0 \mathrm{Aa}$ & $56,0 \mathrm{Aa}$ & $56,0 \mathrm{Aa}$ & 51,1 \\
\hline \multirow{2}{*}{ SSM } & Presente & 43,7 Ba & 56,0 Aa & $56,0 \mathrm{Aa}$ & $56,0 \mathrm{Aa}$ & 52,9 \\
\hline & Ausente & $41,1 \mathrm{Bb}$ & $56,0 \mathrm{Aa}$ & $56,0 \mathrm{Aa}$ & $56,0 \mathrm{Aa}$ & 52,2 \\
\hline \multirow{2}{*}{ NPV } & Presente & 43,7 Ba & $56,0 \mathrm{Aa}$ & 56,0 Aa & $56,0 \mathrm{Aa}$ & 52,9 \\
\hline & Ausente & 41,2 Bb & $56,0 \mathrm{Aa}$ & 56,0 Aa & $56,0 \mathrm{Aa}$ & 52,2 \\
\hline
\end{tabular}

Legenda: *Médias seguidas pela mesma letra maiúscula na linha e minúscula na coluna não diferem entre si pelo teste de Scott-Knott, a $5 \%$ de probabilidade de erro. SEM: sem sintomas de murcha; SLM: sintomas leves de murcha; SMM: sintomas moderados de murcha; SSM: sintomas severos de murcha; NPV: número de dias que a planta permaneceu viva.

entre posição e idade das folhas nas plantas. As folhas foram selecionadas na porção média da planta, usando uma totalmente expandida e sem sintomas de deficiência hídrica, nutricional e com características sadias. A eficiência no uso da água (WUE) foi calculada pela razão entre $A$ e $E$.

\section{Análise estatística}

Anteriormente à análise dos dados foi confirmada a normalidade do conjunto de dados por meio do teste de Kolmogorov-Smirnov e a homogeneidade pelo teste de Bartlett. A análise de variância (ANOVA) foi realizada e as médias foram comparadas pelo teste de Scott-Knott a 5\% de probabilidade de erro.

\section{Resultados e discussões}

\section{Sintomatologia visual}

A análise de variância dos dados revelou que houve interação $(P<0,05)$ entre $o$ uso de hidrogel $e$ as frequências de irrigação para todas as variáveis avaliadas depois de 56 dias. Os resultados demonstram que o hidrogel exerceu influência no surgimento dos sintomas de déficit hídrico. Na presença do hidrogel as mudas de E. dunnii retardaram em média dois dias o surgimento de sintomas (SEM) quando a irrigação foi realizada somente no plantio e até quatro dias para o tratamento com irrigação a cada oito dias (Tabela 1). Nas menores frequências de irrigação não houve diferença com o uso do hidrogel.

Estes resultados, foram semelhantes aos de Navroski et al. [10], em que a utilização do polímero em E. dunnii também respondeu positivamente a escassez de água no solo, adiando os sintomas de déficit hídrico. A maior influência ocorreu quando a irrigação foi efetuada em menor frequência, ou seja, com intervalos maiores. Os resultados também corroboram com Lopes et al. [11], em que avaliando o uso de hidrogel na sobrevivência de mudas clonais de Eucalyptus urograndis, após o plantio em vasos com preenchimento de solo argiloso, mostrou que o polímero possibilitou que as plantas permanecem vivas sem sintomas de falta de água por até 20 dias, cerca de até sete dias a mais do que quando o produto não foi adicionado nas covas de plantio.

Resultado semelhante foi observado nos sintomas leve de murcha (SLM), em que o uso de hidrogel retardou os sintomas na irrigação somente no plantio (0), 8 e 4 dias. Não houve sintomas de murchas superiores ao leve (SLM) na frequência de irrigação 8 dias, ou em irrigações mais frequentes. Contudo, o hidrogel continuou apresentando retardamento dos sintomas mais expressivos de estresse hídrico no tratamento sem 


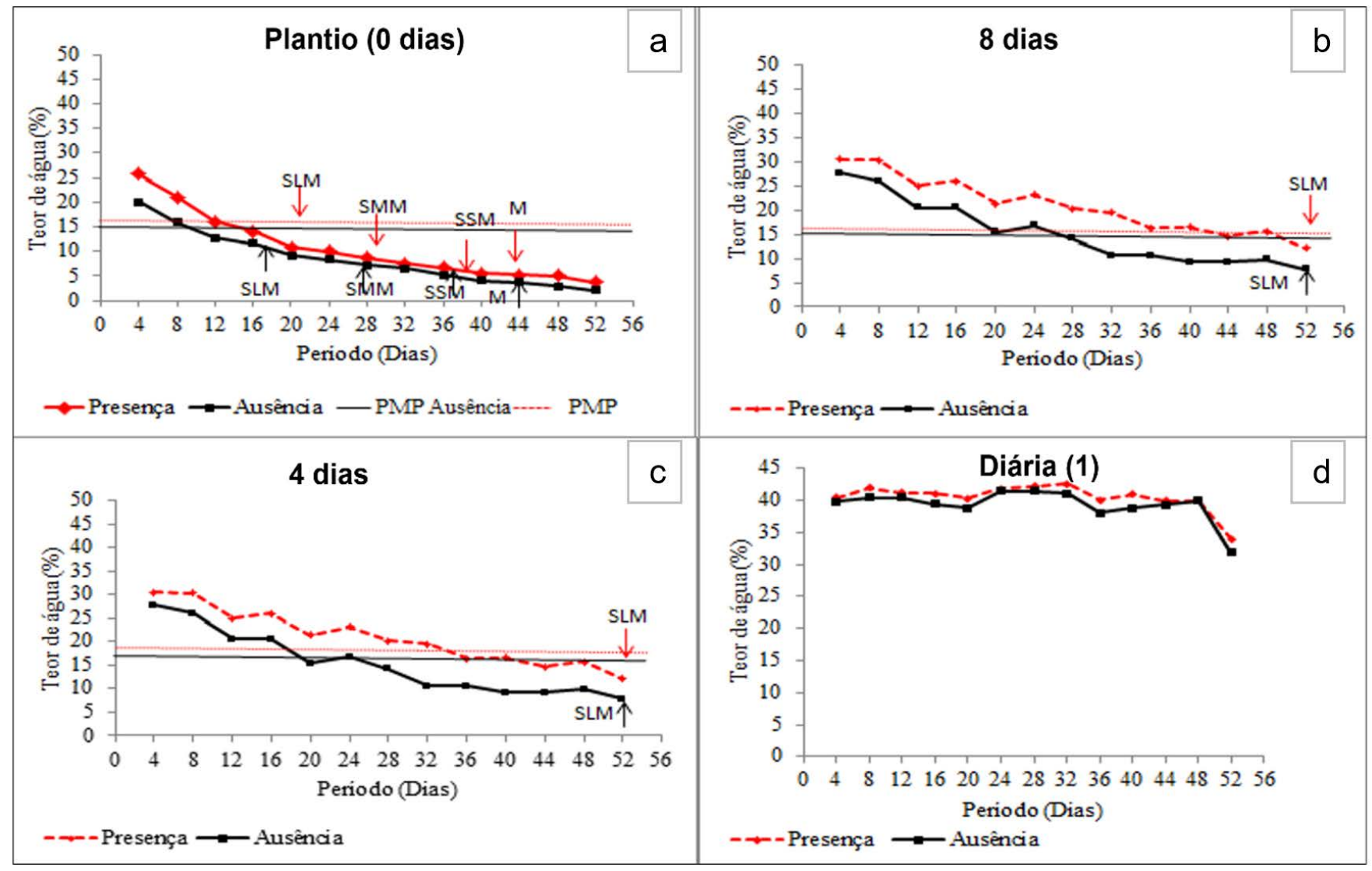

Figura 1. Teor de água no solo e sintomatologia visual em mudas de Eucalyptus dunnii em função da presença ou ausência de hidrogel. a - irrigação somente no plantio; b - irrigação a cada 8 dias; c - irrigação a cada 4 dias e d - irrigação diária.

Figure 1. Soil water content and visual symptomatology in Eucalyptus dunnii plants as a function of the presence or absence of hydrogel. a - irrigation only at planting; $b$ - irrigation every 8 days; $c$ - irrigation every 4 days and $d$ - daily irrigation.

Legenda: SLM: sintomas leves de murcha; SMM: sintomas moderados de murcha; SSM: sintomas severos de murcha; M: planta morta; PMP: ponto de murcha permanente.

Legend: SLM: mild symptoms of wilting; SMM: moderate withering symptoms; SSM: severe wilting symptoms; M: dead plant; PMP: permanent withering point.

irrigação após o plantio (0). Esses resultados mostram que o hidrogel retarda em alguns dias o aparecimento dos efeitos da falta de água.

É importante destacar que na implantação de florestas de Eucalyptus observa-se que o período mais crítico quanto à perda de mudas por falta de água normalmente é nos primeiros 20 dias após o plantio, momento em que a planta está se estabelecendo e com o sistema radicular ainda em formação [12]. Na implantação no campo, pode-se supor que nos casos em que a irrigação é efetuada frequentemente, ou quando a frequência de chuvas é maior, o uso do polímero poderia ser evitado [13]. Contudo, em condições de menor frequência de chuva, ou fazendo-se irrigações mais espaçadas, o uso do polímero pode ser recomendado.

Saad et al. [14] relatam que sob o ponto de vista prático, com o hidrogel os cinco dias a mais em um solo arenoso possibilitaria o adiamento da irrigação e implicaria em menores custos, uma vez que se poderia aguardar por chuvas nesse período. Neste ponto de estresse as plantas ainda têm condição de se recuperarem da deficiência hídrica, diante da ocorrência de chuva.

\section{Teor de água no solo}

Considerando o teor de água no solo, identificou-se variações no armazenamento de água no solo por conta da utilização do hidrogel. De forma geral, as maiores perdas de água foram encontradas para os tratamentos que não fizeram uso do polímero no substrato. A quantidade de água no solo aumentou quando se utilizou o hidrogel, indicando que este atua como condicionante da umidade no solo (Figura 1).

O aumento na capacidade de retenção de água no solo também foi observado por Prevedello e Balena [16]. Com a adição de polímero agrícola no solo a umidade 
Tabela 2. Médias de incremento em diâmetro e altura, massa seca de raízes, caule e folhas, e respectiva área foliar em função da presença (3 g L-1) e ausência $\left(0 \mathrm{~g} \mathrm{~L}^{-1}\right)$ de hidrogel e frequência de irrigação em mudas de Eucalyptus dunnii.

Table 2. Mean increase in diameter, height, dry mass of roots, stem and leaves, and respective leaf area as a function of the presence ( $3 \mathrm{~g} L-1)$ and absence $(0 \mathrm{~g} \mathrm{~L}-1)$ of hydrogel and frequency of irrigation in Eucalyptus dunnii plants.

\begin{tabular}{|c|c|c|c|c|c|c|}
\hline \multirow{2}{*}{\multicolumn{2}{|c|}{ Hidrogel }} & \multicolumn{5}{|c|}{ Frequência de irrigação } \\
\hline & & Plantio (0) & 8 dias & 4 dias & Diária (1) & Média \\
\hline \multirow{3}{*}{$\mathrm{ID}(\mathrm{mm})$} & Presença & $0,88 \mathrm{Da}^{*}$ & $1,01 \mathrm{Ca}$ & $2,95 \mathrm{Ba}$ & 4,02 Aa & 2,21 \\
\hline & Ausência & $0,83 \mathrm{Ba}$ & $0,76 \mathrm{Ba}$ & $2,30 \mathrm{Aa}$ & $2,59 \mathrm{Ab}$ & 1,62 \\
\hline & Média & 0,85 & 0,88 & 2,62 & 3,30 & \\
\hline \multirow{3}{*}{$\mathrm{IH}(\mathrm{cm})$} & Presença & $7,12 \mathrm{Ca}$ & $13,2 \mathrm{Ba}$ & $22,8 \mathrm{Aa}$ & $24,10 \mathrm{Aa}$ & 16,30 \\
\hline & Ausência & $4,47 \mathrm{Cb}$ & $13,0 \mathrm{Ba}$ & $22,0 \mathrm{Aa}$ & $23,07 \mathrm{Aa}$ & 15,35 \\
\hline & Média & 4,79 & 13,1 & 22,4 & 23,50 & \\
\hline \multirow{3}{*}{ MSR (g/planta) } & Presença & 1,47 & 2,50 & 3,58 & 4,78 & $3,08 \mathrm{a}$ \\
\hline & Ausência & 1,02 & 1,59 & 3,14 & 3,82 & $2,39 \mathrm{~b}$ \\
\hline & Média & $1,24 \mathrm{D}$ & $2,05 \mathrm{C}$ & $3,36 \mathrm{~B}$ & $4,30 \mathrm{~A}$ & \\
\hline \multirow{3}{*}{ MSC (g/planta) } & Presença & 1,98 & 1,86 & 3,52 & 4,82 & $3,04 \mathrm{a}$ \\
\hline & Ausência & 0,88 & 1,44 & 3,09 & 3,09 & $2,11 \mathrm{~b}$ \\
\hline & Média & $1,43 \mathrm{~B}$ & $1,65 \mathrm{~B}$ & $3,30 \mathrm{~A}$ & $3,95 \mathrm{~A}$ & \\
\hline \multirow{3}{*}{ MSF (g/planta) } & Presença & 1,98 & 2,50 & 4,52 & 5,21 & $3,55 \mathrm{a}$ \\
\hline & Ausência & 1,05 & 2,04 & 4,09 & 4,98 & $3,04 \mathrm{~b}$ \\
\hline & Média & $1,51 \mathrm{D}$ & $2,27 \mathrm{C}$ & $4,30 \mathrm{~B}$ & $5,09 \mathrm{~A}$ & \\
\hline \multirow{3}{*}{$\mathrm{AF}\left(\mathrm{cm}^{2} /\right.$ planta $)$} & Presença & 154,6 & 265,7 & 747,1 & 810,0 & 494,3 a \\
\hline & Ausência & 84,1 & 227,5 & 636,1 & 695,8 & $410,1 \mathrm{~b}$ \\
\hline & Média & 119,3 D & $246,6 \mathrm{C}$ & $691,6 \mathrm{~B}$ & $752,9 \mathrm{~A}$ & \\
\hline
\end{tabular}

Legenda: *Médias seguidas pela mesma letra maiúscula na linha e minúscula na coluna não diferem entre si pelo teste de Scott-Knott, a 5\% de probabilidade de erro. ID: incremento em diâmetro; IH: incremento em altura; MSR: massa seca radicular; MSC: massa seca caulinar; MSF: massa seca foliar; AF: área foliar.

Legend: *Means followed by the same letter in uppercase and lowercase line in the column do not differ by Scott-Knott test at $5 \%$ probability of error. ID: increment in diameter; IH: increase in height; MSR: root dry mass; MSC: cauline dry mass; MSF: leaf dry mass; AF: leaf area.

aumentou progressivamente chegando a duplicar a capacidade de armazenamento de água, demonstrando a grande capacidade do polímero em reter e conservar água no solo por períodos apreciáveis de evaporação.

Analisando individualmente o teor de água no solo na presença e na ausência do hidrogel é notável que os diferentes níveis de umidade do solo afetaram significantemente todas as variáveis de sintomatologia visual observadas durante o período experimental. Independente da condição de solo em que as mudas foram submetidas, o início dos sintomas ocorreu quando a umidade volumétrica do solo ultrapassou os valores dos Pontos de Murcha Permanente (PMP).

Quando a irrigação ocorreu apenas no plantio (0), a presença do hidrogel promoveu um atraso nos sintomas visuais de déficit hídrico avaliados. Os sintomas leves de murcha (SLM) apareceram aproximadamente aos 20 dias após o plantio, quando o teor de água no solo chegou a 10,8 \%. Quando comparado à ausência do mesmo, esse sintoma apareceu três dias antes, com 11,7\% de umidade. $\mathrm{O}$ aparecimento dos sintomas moderados de murcha (SMM), na presença de hidrogel ocorreu aos 28 dias após o plantio quando o teor de água foi de $8,7 \% \mathrm{e}$ na ausência do mesmo aos 25 dias após o plantio com uma umidade de $8,0 \%$.

Considerando os sintomas severos de murcha (SSM), observou-se que na presença de hidrogel houve um retardamento de aproximadamente três dias. Os sintomas surgiram quando o teor de água chegou a 6,2 $\%$, aos 39 dias após o plantio, sendo que na ausência este ocorreu aproximadamente aos 36 dias e com teor de umidade de 5,5\%. Quando se fez uso do polímero hidroretentor, constatou-se que a morte das mudas (M) ocorreu aproximadamente aos 44 dias após o plantio quando o teor de água no solo atingiu 5,0 \%. Já sem a 
utilização do hidrogel esses sintomas foram observados aos 41 dias, com $4,5 \%$ de umidade.

O fato de as plantas sobreviverem abaixo do PMP é possível devido ao ajuste osmótico, que se desenvolve lentamente em resposta à desidratação do tecido causado pelo déficit hídrico. As folhas que são capazes de realizar esse ajuste podem manter o turgor sob potenciais hídricos mais baixos [17].

À medida que o solo seca, torna-se mais difícil às plantas absorverem água, porque aumenta a força de retenção e diminui a disponibilidade de água no solo às plantas [18]. Desse modo, nem toda a água que o solo armazena é disponível às plantas [19].

\section{Atributos morfométricos}

Em relação às características de altura e diâmetro de coleto das plantas os resultados mostraram que ambos os incrementos foram afetados pelas frequências hídricas aplicadas e o uso de hidrogel, havendo interação entre os fatores $(P=0,0001)$. Para massa seca radicular, caulinar e foliar e área foliar houve efeito para os fatores de forma isolada (Tabela 2).

O incremento em diâmetro do coleto (ID) das mudas de E. dunnii foi influenciado pelo uso do polímero hidroretentor somente na irrigação diária. $O$ uso de irrigação apresentou efeito esperado, quanto mais frequentes as irrigações, maior 0 incremento. Plantas submetidas à deficiência hídrica, ou seja, quando a irrigação ocorreu apenas no plantio e a cada 8 dias, apresentaram os menores valores desta variável. O incremento em altura $(\mathrm{IH})$ apresentou comportamento similar ao diâmetro do coleto. A presença do hidrogel possibilitou um ganho considerável de altura em relação à sua ausência quando a irrigação foi realizada somente no plantio, demonstrando que as mudas na condição de estresse hídrico extremo se desenvolveram melhor na presença do polímero.

Em relação à massa seca radicular, caulinar e foliar, e área foliar, a adição de hidrogel elevou em aproximadamente $25 \%$ as médias, demonstrando o efeito positivo do polímero no crescimento das plantas e acúmulo de massa seca, por conta do fornecimento adequado de água. Como esperado, à medida que as mudas foram irrigadas com mais frequência, aumentaram as médias de todas estas variáveis, sendo que a maior disponibilidade hídrica possibilitou o maior desenvolvimento das plantas.

De todos os recursos que as plantas necessitam para crescer e desenvolver suas funções fisiológicas, a água é o mais abundante e, ao mesmo tempo, o mais limitante [15]. Neste sentido, a prática de irrigação reflete o fato de que a água é um recurso-chave que limita a produtividade dos plantios florestais.

\section{Trocas gasosas}

Analisando a taxa fotossintética em relação às frequências de irrigação pode-se observar efeito direto sobre este processo fisiológico (Figura 2a). A taxa fotossintética declinou de forma rápida logo após a implantação do experimento até o final, principalmente quando a irrigação ocorreu somente no plantio (0).

$\mathrm{Na}$ presença do polímero observou-se maior taxa fotossintética para as plantas irrigadas mais frequentemente. A maior taxa fotossintética foi observada na irrigação diária (1); à medida que se aumentou o intervalo das irrigações, ou especialmente no tratamento com irrigação somente no plantio (0), a taxa fotossintética decaiu, demonstrando o efeito direto da disponibilidade de água sobre a fotossíntese. Já na ausência de hidrogel o tratamento irrigado somente no plantio (0) obteve o menor, como esperado, e o melhor desempenho fotossintético ocorreu na frequência de 4 dias (4).

O resultado obtido no presente estudo é semelhante ao encontrado por Arbona et al. [21], em que concluíram que a presença do hidrogel contribuiu não só para a sobrevivência como resultou em maior crescimento e fotossíntese em plantas jovens de Poncirus trifoliata [L.] Raf. x Citrus sinensis [L.] Osb. Contudo, Apostol et al. [20] reportaram inexistir efeitos benéficos no crescimento e nas trocas gasosas em mudas de Quercus rubra submetidas ao estresse hídrico.

Os efeitos do hidrogel na fisiologia de espécies lenhosas apresentam controvérsias. Enquanto Apostol et al. [20] reportaram inexistir efeitos benéficos no crescimento e nas trocas gasosas em mudas submetidas ao estresse hídrico, Arbona et al. [21] concluíram que a presença do hidrogel contribuiu não só para a sobrevivência como resultou em maior crescimento e fotossíntese em plantas cítricas.

A transpiração (E) foi maior conforme a disponibilidade de água, conforme esperado. Plantas cultivadas sem o polímero hidroretentor, no geral transpiraram mais do que quando se fez uso do hidrogel no solo de cultivo (Figura 2b). A menor taxa transpiratória foi observada quando a irrigação ocorreu apenas no plantio (0), seguido da irrigação a cada 8 dias (8).

Alguns autores [22], [23], [24] constataram que o manejo com déficit hídrico contribui para a redução da transpiração de Eucalyptus. Tatagiba et al. [25] apontaram que a taxa transpiratória em clones de Eucalyptus sp. na época chuvosa foi maior em relação à época seca. Esse fato pode ser devido a ocorrência do excedente hídrico na época chuvosa, enquanto na época seca não 

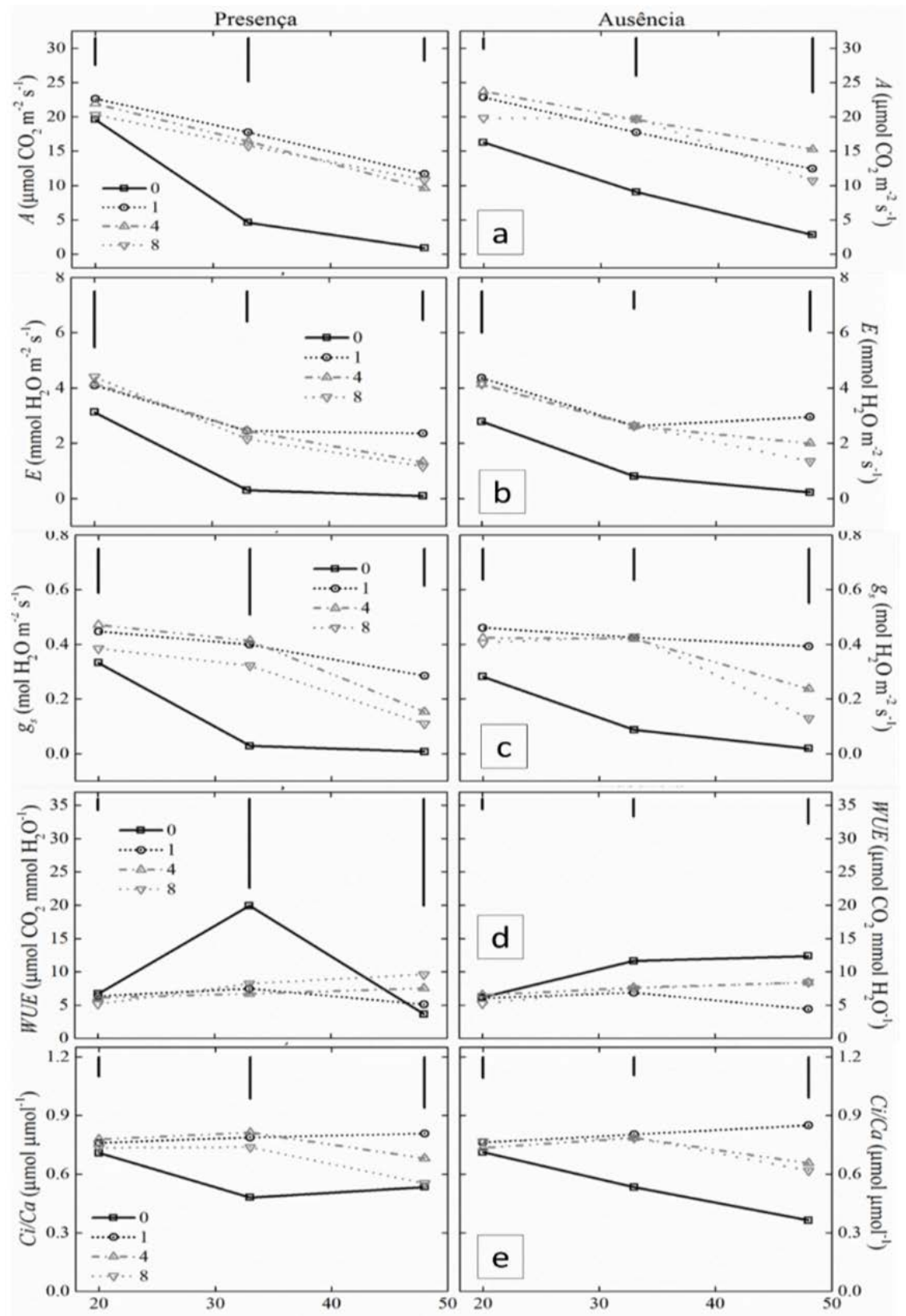

Periodo (dias)

Figura 2. a - taxa fotossintética (A), b - transpiração (E), c - condutância estomática (gs), d - eficiência no uso da água (WUE), e - relação entre a concentração intercelular e atmosférica de $\mathrm{CO}_{2}(\mathrm{Ci} / \mathrm{Ca})$ em mudas de Eucalyptus dunnii em função da presença ou ausência de hidrogel submetidas a diferentes frequências de irrigação. As barras flutuantes indicam a diferença mínima significativa entre as frequências de irrigação, pelo teste de Scott-Knott $(P<0,05)$.

Figure 2. a - photosynthetic rate (A), b - transpiration (E), c - stomatal conductance (gs), d - water use efficiency (WUE), e- relationship between intercellular and atmospheric $\mathrm{CO}_{2}$ concentration $(\mathrm{Ci} / \mathrm{Ca})$ in Eucalyptus dunnii plants as a function of the presence or absence of hydrogel submitted to different irrigation frequencies. Floating bars indicate the minimum significant difference between irrigation frequencies by Scott-Knott test $(\mathrm{P}<0.05)$.

havia disponibilidade suficiente de água no solo para os clones manterem altas taxas de transpiração.

Em relação à condutância estomática (gs) das mudas de E. dunnii, observou-se queà medida que a disponibilidade de água foi diminuindo, também diminuiu a condutância estomática (Figura 2c). Independente da presença ou ausência do polímero, os maiores valores de condutância estomática foram verificados nas frequências de 1, 4 e 8 dias, respectivamente.

O fechamento estomático é uma estratégia utilizada pela planta para reduzir a perda de água, porém, consequentemente acarreta em queda na capacidade 
dos estômatos permitirem trocas gasosas entre a planta e o ambiente. Assim, a redução da disponibilidade hídrica no solo reduz a condutância estomática com implicações diretas na transpiração, fotossíntese e temperatura das folhas, causando prejuízos em caso de secas severas [26].

Otto et al. [27] observaram que em área seca o déficit hídrico foi um fator limitante para a abertura estomática, - que contribuiu para a queda na assimilação de carbono pela fotossíntese. Ao contrário da área úmida, que além de proporcionar controle estomático, apresentou maiores valores das taxas fotossintéticas e produtividade.

A eficiência no uso da água (WUE) foi afetada diretamente pelas frequências de irrigação, não sendo muito influenciado pelo uso de hidrogel (Figura 2d). Quando a irrigação ocorreu somente no plantio (0) com o uso do hidrogel, houve um acréscimo da WUE até o $35^{\circ}$ dia, apresentando na sequência uma queda. Na ausência do polímero houve uma elevação até o $35^{\circ}$, mantendo-se inalterada até o fim do período experimental.

É provável que essa eficiência, neste caso, seja justificada pela menor taxa de transpiração das plantas. $O$ uso da água compreende os processos de transpiração e de evaporação da água no solo [28]. Assim, o WUE é sensível às condições ambientais e consequentemente, às alterações ambientais [29]. Quando as plantas percebem o déficit hídrico ativam múltiplas respostas para sincronizar seu desenvolvimento e suas atividades moleculares, visando garantir sua sobrevivência [30].

Os resultados obtidos para $\mathrm{Ci} / \mathrm{Ca}$ (Figura 2e) mostram que independente da presença ou ausência do hidrogel no solo de cultivo, no geral a redução de $\mathrm{Ci} / \mathrm{Ca}$ ocorreu devido ao fechamento estomático. Este resultado demonstra que a fotossíntese continuou a ocorrer mesmo com os estômatos fechados, reduzindo assim a concentração intercelular de $\mathrm{CO}_{2}$. Como os valores de $\mathrm{Ci} / \mathrm{Ca}$ não se elevaram, podemos inferir que durante o período de avaliação a redução da fotossíntese foi somente estomática, não havendo danos ao aparato fotossintético.

Entender como as plantas respondem ao déficit hídrico é importante para melhorar o desempenho e produtividade das culturas. Técnicas de manejo adequadas e o melhoramento genético são ferramentas para melhorar a eficiência do uso de recursos pelas plantas, inclusive da água [31]. Estudos ecofisiológicos e hidrológicos de longo prazo são necessários para adequar as técnicas de produção florestal e otimizar o uso da água, aumentando assim a produtividade florestal [32].

\section{Conclusão}

O polímero hidroretentor possibilitou o adiamento de todos os sintomas de déficit hídrico avaliados, em até quatro dias para o aparecimento dos sintomas iniciais por conta do maior armazenamento de água no solo. A adição do polímero proporcionou também a melhoria da qualidade das mudas, promovendo maior acúmulo de massa seca.

As trocas gasosas foram afetadas pela disponibilidade de água, pois variaram em função da frequência de irrigação, independente da presença ou ausência do hidrogel. $O$ déficit hídrico foi um fator limitante para a abertura estomática e contribuiu para a queda na assimilação de carbono pela fotossíntese.

Assim, recomenda-se a utilização de polímeros hidroretentores no plantio de mudas, por aumentar a retenção de água no solo e possibilitar o adiamento dos sintomas de estresse hídrico, conjuntamente ao melhor desenvolvimento das plantas. Porém, são necessários estudos em condições reais de campo e acompanhamento das plantas por um período maior de tempo.

\section{Agradecimentos}

Os autores agradecem a FAPESC pelo financiamento do grupo de pesquisa Gestão de florestas plantadas e naturais (PAP N ${ }^{\circ}$ 2019TR657).

\section{Referências}

[1] IBÁ, "Relatório 2017", Indústria Brasileira de Árvores, 2017. [Online]. Disponível em: https://www.iba.org/datafiles/ publicacoes/pdf/iba-relatorioanual2017.pdf

[2] J. C. Gonçalez, G. L. Santos, F. G. Silva Junior, I. S. Martins, J. A. Costa. "Relações entre dimensões de fibras e de densidade da madeira ao longo do tronco de Eucalyptus urograndis,". Scientia Forestalis, v. 42, no. 101, pp. 81-89, 2014.

[3] T. F. Assis, "Melhoramento genético de Eucalyptus: desafios e perspectivas", Ann. $3^{\circ}$ Encontro Brasileiro de Silvicultura, 2014, pp. 113-133.

[4] L. D. Diaz-López, V. Gimeno, V. Lidón, I. Simón, V. Martínez, F. G. Sánchez, "The tolerance of Jatropha curcas seedlings to $\mathrm{NaCl}$ : an ecophysiological analysis," Plant Physiology and Biochemistry, v. 54, no. 2, pp. 34-42, 2012.

[5] F. S. Matos et al. "Estratégia morfofisiológica de tolerância ao déficit hídrico de mudas de pinhão manso," Magistra, v.26, no. 1, pp. 19-27, 2014.

[6] O. M. R. Cabral et al. "The energy and water balance of a Eucalyptus plantation in southeast Brazil," Hydrological Sciences Journal, v. 388, pp. 208-216, 2010. 
[7] F. A. Buzetto, J. M. C. Bizon, F. Seixas "Avaliação de polímero adsorvente à base de acrilamida no fornecimento de água para mudas de Eucalyptus urophylla em pós-plantio," Circular Técnica IPEF, no. 195, 2002. Disponível em: http:// www.ipef.br/publicacoes/ctecnica/nr195.pdf

[8] J. L. M. Gonçalves, J. L. Stape, J. P. Laclau, P. Smethurst, L. Gava, "Silvicultural effects on the productivity and wood quality of eucalypt plantations," Forest Ecology Management, v. 193, no. 1-2, pp. 45-61, 2004.

[9] I. Wendling, L. F. Dutra, Produção de mudas de eucalipto, Brasil: Embrapa Florestas, 2010.

[10] M. C. Navroski, M. M. Araújo, F. S. Cunha, A. L. P. Berghetti, M. O. Pereira, "Influência do polímero hidroretentor na sobrevivência de mudas de Eucalyptus dunnii sob diferentes manejos hídricos", Revista Nativa, v. 2, no. 2, pp. 108 - 113, 2014.

[11] J. L. Lopes, M. R. Silva, J. C. C. Saad, T. S. Angélico, "Uso de hidrogel na sobrevivência de mudas de Eucalyptus urograndis produzidas com diferentes substratos e manejos hídricos", Ciência Florestal, v. 20, no. 2, pp. 217224, 2010.

[12] M. Fernández, R. T. Martín, P. Alesso, "Adaptación a la sequía y necesidades hídricas de Eucalyptus globulus Labill. en Huelva," Boletín del CIDEU, v. 9, no. 8, pp.31-41, 2010.

[13] M. C. Navroski et al. "Uso de hidrogel possibilita redução da irrigação e melhora o crescimento inicial de mudas de Eucalyptus dunnii Maiden," Scientia Forestalis, v. 43, no. 106, pp. 467 - 476, 2015.

[14] J. C. C. Saad, J. L. W. Lopes, T. A. Santos, "Manejo hídrico em viveiro e uso de hidrogel na sobrevivência pós-plantio de Eucalyptus urograndis em dois solos diferentes", Engenharia Agrícola, v. 29, no. 3, pp.404-411, 2009.

[15] G. B. Kerbauy, Fisiologia vegetal, Brasil: Guanabara, 2009.

[16] C. L. Prevedello, S. P. Balena, "Efeitos de polímeros hidrorretentores nas propriedades físico-hídricas de dois meios porosos", Revista Brasileira de Ciência do Solo, v. 24, pp. 251-258, 2000.

[17] L. Taiz, E. Zeiger, Fisiologia vegetal, 5 eds., Brasil: Artmed, 2014. 918 p.

[18] H. BERGAMASCHI, "Desenvolvimento de déficit hídrico em culturas", em Agrometeorologia aplicada à irrigação, 1 ed. Brasil: UFRGS, 1992, pp. 25-32.

[19] R. Carlesso, "Absorção de água pelas plantas: água disponível versus extraível e a produtividade das culturas", Ciência Rural, v.25, no.1, pp.183-188, 1995.

[20] K. G. Apostol, D. F. Jacobs, K. Dumroese, "Root desiccation and drought stress responses of bareroot Quercus rubra seedlings treated with hydrophilic polymer root dip," Plant and Soil, v. 315, pp. 229-240, 2009

[21] V. Arbona et al. "Hydrogel substrate amendment alleviates drought effects on young citrus plants," Plant and Soil, v. 270, no. 1-2, pp. 73-82, 2005.

[22] M. R. Silva, A. E. Klar, J. R. Passos, "Efeitos do manejo hídrico e da aplicação de potássio nas características morfofisiológicas de mudas de Eucalyptus grandis Hill ex. Maiden", Revista Irriga, v. 9, no. 1, pp. 31-40, 2004.
[23] A. P. O'Grady, D. Worledgeb, M. Battagliab, "Constraints on transpiration of Eucalyptus globulus in southern Tasmania, Australia," Agricultural and Forest Meteorology, v. 148, no. 3, pp. 453-465, 2008.

[24] K. C. Tonello, J. Teixeira Filho, "Transpiração e condutância estomática de Eucalyptus sp. em resposta à radiação global e diferentes condições hídricas", Revista Irriga, v. 18, no. 4, pp. 607-623, 2013

[25] S. D. Tatagiba, J. E. M. Pezzopane, R. Penchel, E. F. Reis, "Variabilidade diurna e sazonal das trocas gasosas e do potencial de água das folhas de clones de Eucalyptus", Engenharia na Agricultura, v. 16, no. 2, pp. 225-237, 2007.

[26] M. G. Santos et al. "Photosynthetic parameters and leaf water potential of five common beans genotypes under mild water deficit," Biologic Plantarum, v. 53, no. 2, pp. 229-236, 2009.

[27] M. S. G. Otto, R. M. Hubbard, D. Binkley, J. L. Stape, "Dominant clonal Eucalyptus grandis $\mathrm{x}$ urophylla trees use water more efficiently," Forest Ecology and Management, v. 328, pp. 117-121, 2014.

[28] S. Roberts, R. Barton-Johnson, M. Mclarin, S. Read, "Predicting the water use of Eucalyptus nitens plantation sites in Tasmania from inventory data, and incorporation of water use into a forest estate model," Forest Ecology and Management, v. 343, pp. 110-122, 2015.

[29] P. B. Laclau et al. "Potassium fertilization increases water-use efficiency for stem biomass production without affecting intrinsic water-use efficiency in Eucalyptus grandis plantations," Forest Ecologyand Management, v. 364, pp.77-89, 2016.

[30] A. E. Valdés, S. Irar, J. Majada, M. Pages, "Drought tolerance acquisition in Eucalyptus globulus (Labill.): a research on plant morphology, physiology and proteomics," Journal of proteomics, v. 79, pp. 263-276, 2013.

[31] M. M. Chaves, J. Flexas, C. Pinheiro, "Photosynthesis under drought and salt stress: regulation mechanisms from whole plant to cell," Annals of Botany, v. 103, no. 4, pp. 551-560, 2009.

[32] A. C. Almeida, V. J. Soares, J. J. Landsberg., G. D. Rezende, "Growth and water balance of Eucalyptus grandis hybrid plantations in Brazil during a rotation for pulp production," Forest Ecology and Management, v. 251, no. 1-2, pp. 1021, 2007. 